\title{
PEMASARAN KACANG TANAH DI DISTRIK BUGI KABUPATEN JAYAWIJAYA
}

\author{
Ilanus Medlama \\ Benny Adrian Berthy Sagay \\ Yolanda Pinky Ivana Rori
}

Naskah diterima melalui Website Jurnal Ilmiah agrisosioekonomi@unsrat.ac.id

\begin{abstract}
The purpose of this study was to describe the marketing of peanuts in Bugi District, Jayawijaya Regency. The study was conducted from January to March 2019. Data and information were collected from primary sources and secondary sources. The selection of respondents was done purposevely. Primary data was collected from interviews with 20 farmers who are farmers as well as sellers of peanuts based on a list of questions that had been prepared and direct observations on marketing activities of peanuts at the study site. Secondary data was collected from the Bugi District office, Statistics report of Jayawijaya Regency Central Bureau, the internet through google search and google scholar to obtain journal article and thesis those related to the topic of peanut marketing. The analysis used is a qualitative analysis method. The results of the study show that farmers are easier to obtain market information about prices and act as determinants of prices because farmers sell directly to the market by bringing their own produce so that it does not require costs to obtain price information on the market. ${ }^{-* p r m *}$
\end{abstract}

Keywords: marketing of peanuts, Bugi District, Jayawijaya Regency

\begin{abstract}
ABSTRAK
Tujuan penelitian ini adalah untuk mendeskripsikan pemasaran kacang tanah di Distrik Bugi Kabupaten Jayawijaya. Penelitian dilakukan bulan Januari sampai dengan Maret 2019. Data dan informasi dikumpulkan dari sumber primer dan sumber sekunder. Pemilihan responden dilakukan secara sengaja. Data primer dikumpulkan dari hasil wawancara pada 20 petani sekaligus sebagai penjual kacang tanah berdasarkan daftar pertanyaan yang telah dipersiapkan dan pengamatan langsung pada kegiatan pemasaran kacang tanah di lokasi penelitian. Data sekunder dikumpulkan dari kantor Distrik Bugi, laporan Badan Pusat Statistik Kabupaten Jayawijaya, internet melalui google search dan google scholar untuk mendapatkan artikel jurnal dan skripsi yang berkaitan dengan topik pemasaran kacang tanah. Analisis yang dipakai adalah metode analisis kualitatif. Hasil penelitian menunjukkan petani lebih mudah mendapatkan informasi pasar mengenai harga dan bertindak sebagai penentu harga karena petani menjual langsung ke pasar dengan membawa hasil produksinya sendiri sehingga tidak membutuhkan biaya untuk mendapatkan informasi harga di pasar. ${ }^{-* e p r m^{*}}$
\end{abstract}

Kata kunci: pemasaran kacang tanah, Distrik Bugi, Kabupaten Jayawijaya 


\section{PENDAHULUAN}

\section{Latar Belakang}

Pertanian merupakan salah satu sektor didalam pembangunan nasional, pada dasarnya bertujuan untuk memenuhi kebutuhan pangan masyarakat, memenuhi kebutuhan bahan baku yang semakin berkembang, meningkatkan devisa ekspor hasil-hasilnya dan memperluas kesempatan kerja serta sekaligus mendorong peningkatan dan pemerataan pendapatan bagi masyarakat.

Pembangunan pertanian tidak hanya dititik beratkan pada tingkat produksi dan perluasan lapangan kerja, tetapi juga bertujuan untuk memperluas pasar produk pertanian baik ditingkat lokal maupun nasional, sehingga dalam rangka menghadapi persaingan yang semakin kompetitif, tataniaga mempunyai peran penting dalam meningkatkan daya saing produk (Ginting, 2015).

Kacang tanah (Arachis hypogeae L) merupakan komoditas pertanian yang sangat dibutuhkan oleh masyarakat, baik sebagai bahan makanan manusia maupun bahan baku industri. Kacang tanah termasuk komoditas yang mudah rusak sehingga perlu penanganan khusus sama halnya seperti golongan palawija yang lain.

Sektor pertanian di Kabupaten Jayawijaya merupakan salah satu sektor utama yang berkontribusi dalam menyediakan kebutuhan pangan masyarakat, pembangunan perekonomian daerah dan memberikan sumbangan peningkatan pendapatan daerah terutama bagi penyediaan lapangan kerja.

Distrik Bugi adalah salah satu Distrik di Kabupaten Jayawijaya yang didalamnya terdapat 8 (delapan) kampung, dan 4 (empat) kampong diantaranya mengusahakan kacang tanah oleh sebagian petani di masing-masing kampung yakni Kampung Bugi, Kampung Kodlangga, Kampung Totni, Kampung Tagulik sebagai mata pencaharian utama selain komoditi Ubi Jalar, Jagung, sayuran dan jenis buah-buahan lainnya seperti Buah Merah (Toi), Jeruk (Lemon), Ketimun
(Nggidlu), Kelapa Hutan (Weramo), dan lainlain. Kacang tanah di gunakan sebagai makanan ringan atau tambahan yang diminati oleh konsumen, bagi produsen dan pedagang sebagai sumber penghasilan.

Masyarakat Kabupaten Jayawijaya di Distrik Bugi merupakan penduduk yang agraris memiliki sumber daya alam yang baik, pertanian adalah salah satu sektor ketergantungan kehidupan dalam menyediakan kebutuhan pangan masyarakat di Distrik Bugi selain peternakan. Berbagai upaya strategis diperlukan untuk meningkatkan produksi bahan pangan, sehingga ancaman kerawanan pangan daerah terlebih khusus di Kabupaten Jayawijaya bisa dicegah. Karena sektor pertanian menyerap tenaga yang amat besar dan masyarakat masih membutuhkan produk-produk pertanian untuk bahan pangan (Limbong 1987).

Pengembangan produksi pangan diarahkan sebagai penghasil aneka ragam bahan pangan dengan kualitas dan kuantitas yang semakin meningkat dalam rangka memelihara kemantapan swasembada pangan dan memperbaiki keadaan gizi masyarakat serta sebagai sumber bahan baku bagi agroindustri dalam rangka menunjang program industrialisai (Aryani, 2009).

Usahatani di Distrik Bugi sebagai lokasi penelitian terlihat sangat tradisional mempengaruhi pemanfaatan lahan yang tergolong sangat kecil dan mempengaruhi juga peningkatan produksi kacang tanah dikarenakan kurangnya penerapan sistem agribisnis secara optimal.

Untuk menciptakan kepuasan kepada produsen, konsumen, maupun pedagang besar haruslah mengambil keuntungan yang wajar dan mengadakan efisiensi dalam menjalankan usahanya. Hal inilah yang menentukan kepuasan kepada produsen, konsumen, maupun kepada pedagang eceran. Untuk memperoleh informasi diperlukan serangkaian data melalui suatu penelitian yang mendalam perihal masalah tataniaga tersebut . Hal ini sangat penting diperhatikan dalam upaya peningkatan kesejahteraan petani dan masyarakat. Sehubungan dengan hal tersebut maka beberapa produksi komoditi 
pertanian yang bernilai tinggi atau yang mempunyai keunggulan seperti hasil pangan mendapat perhatian khusus. Oleh karena itu peneliti tertarik untuk mengetahui pemasaran kacang tanah yang ada di Distrik Bugi, Kabupaten Jayawijaya.

\section{Perumusan Masalah}

Berdasarkan latar belakang diatas, maka yang menjadi perumusan masalah adalah Bagaimana pemasaran kacang tanah di Distrik Bugi Kabupaten Jayawijaya.

\section{Tujuan Penelitian}

Tujuan penelitian ini adalah untuk mengetahui pemasaran kacang tanah di Distrik Bugi Kabupaten Jayawijaya.

\section{Manfaat Penelitian}

Manfaat penelitian ini adalah sebagai sumber informasi bagi:

1. Produsen dan pengecer untuk mengetahui fungsi dan saluran pemasaran kacang tanah di lokasi penelitian.

2. Peneliti, sebagai suatu pengetahuan untuk mengetahui fungsi, lembaga dan saluran pemasaran kacang tanah.

3. Mahasiswa atau yang memerlukan dapat dijadikan referensi kajian dalam bidang penelitian serupa.

\section{METODE PENELITIAN}

\section{Waktu dan Tempat Penelitian}

Penelitian dilakukan bulan Januari sampai dengan Maret 2019 pada pemasaran kacang tanah di Distrik Bugi Kabupaten Jayawijaya.

\section{Sumber dan Jenis Data}

Data dan informasi dikumpulkan dari sumber primer dan sumber sekunder. Data primer dikumpulkan dari pemasar kacang tanah berdasarkan daftar pertanyaan (questioner) yang akan dipersiapkan, Jenis-jenis data primer meliputi data/informasi tentang penerapan subsistem pemasaran perunit. Sedangkan data sekunder dikumpulkan dari Pemerintah Distrik, laporan statistik instansi teknis maupun instansi lain yang terkait serta penelusuran Studi Pustaka yang terkait dengan judul.

\section{Konsep Pengukuran Variabel}

Variabel-variabel yang diukur dalam penelitian ini adalah

1. Saluran pemasaran yaitu lembaga pemasaran yang dilalui barang dalam penyaluran komoditi kacang tanah dari petani sampai kepada konsumen.

2. Pelaku pemasaran adalah golongan produsen dan pedagang kacang tanah. Seperti petani (produsen), pedagang pengumpul, dan pedagang eceran.

3. Pasar adalah lokasi geografis, dimana tempat bertemunya para penjual dan pembeli untuk melakukan transaksi jual beli dan mengamati harga dari komoditi kacang tanah.

4. Biaya pemasaran adalah seluruh jenis biaya yang dikeluarkan oleh lembaga pemasaran dalam kegiatan pemasaran kacang tanah $(\mathrm{Rp} / \mathrm{Kg})$. Seperti tingkat harga beli pedagang yang di hitung dari harga rata-rata pembelian kacang tanah $(\mathrm{Rp} / \mathrm{Kg})$ dan keuntungan lembaga pemasaran $(\mathrm{Rp} / \mathrm{Kg})$.

\section{Metode Analisis Data}

Penelitian ini menggunakan metode analisis kualitatif dan kuantitatif.

1. Analisis kualitatif dilakukan dengan pengamatan langsung terhadap keadaan sistem pemasaran yang meliputi lembaga pemasaran dan fungsi yang dilakukan oleh masing-masing lembaga pemasaran, saluran pemasaran, perilaku pasar.

2. Untuk mengetahui biaya menggunakan Analisis kuantitatif. Dengan rumus:

$$
\mathrm{TC}=\mathrm{FC}+\mathrm{VC}
$$

Dimana: $\mathrm{TC}=$ Biaya Total

$$
\begin{aligned}
& \mathrm{FC}=\text { Biaya Tetap } \\
& \mathrm{VC}=\text { Biaya variable }
\end{aligned}
$$

\section{HASIL DAN PEMBAHASAN}

\section{Keberadaan Wilayah dan Letak Geografis}

Pada umumnya Kabupaten Jayawijaya dibentuk berdasarkan Undang - Undang Nomor 12 Tahun 1969, tentang pembentukan Provinsi Otonom Irian Barat dan Kabupaten-Kabupaten Otonom di Provinsi Irian Barat. Berdasarkan pada Undang-undang tersebut, Kabupaten Jayawijaya terletak pada garis meridian $138.30^{\circ}$ - $139-40^{\circ}$ BT dan $3.45^{\circ}-4.20^{\circ}$ LS dengan 
ketinggian 1.650 di atas permukaan laut yang memiliki daratan seluas 13.925,31 $\mathrm{km}^{2}$. Kabupaten Jayawijaya adalah salah satu kabupaten di provinsi Papua, Indonesia. Ibu kota kabupaten ini terletak di Wamena (Lembah Baliem). Distrik Bugi merupakan 1 (satu) dari 40 wilayah Distrik di Kabupaten Jayawijaya, letaknya $36 \mathrm{~km}$ sebelah utara dari ibu kota kabupaten. Distrik Bugi terbagi atas 8 kampung yaitu Manda, Air Garam, Totni, Walak Selatan, Bugi, Kodlangga, Tagulik, dan Dewene. Berdasarkan jarak ibu kota kabupaten ke kampung Dewene, kampung terjauh dengan jarak $45 \mathrm{~km}$, sedangkan kampung Walak Selatan adalah kampung terdekat dengan jarak 33 km, Luas wilayah Distrik Bugi 48.383 Ha.

\section{Karakteristik Responden}

Karakteristik responden sangat mempengaruhi kelancaran pengembangan pemasaran komoditi kacang tanah. Karakteristik petani sebagai pelaku usaha tani dan pedagang sebagai penyalur di dalam lembaga pemasaran. Karakteristik responden terutama meliputi kelompok umur, tingkat pendidikan, jumlah anggota keluarga. Jumlah sampel yang menjadi objek penelitian sebanyak 20 orang responden.

1. Umur

$$
\text { Persentase responden menurut }
$$
karakteristik usia di daerah penelitian dapat dilihat pada Tabel 1 .

Tabel 1. Persentase Responden Menurut Umur Di Lokasi Penelitian, Tahun 2019

\begin{tabular}{lcc}
\hline $\begin{array}{c}\text { Kelompok } \\
\text { Usia }\end{array}$ & $\begin{array}{c}\text { Jumlah Responden } \\
\text { (orang) }\end{array}$ & Persentase (\%) \\
\hline $21-30$ & 2 & 10 \\
$31-40$ & 6 & 30 \\
$41-50$ & 10 & 50 \\
$>50$ & 2 & 10 \\
\hline Jumlah & 20 & 100 \\
\hline
\end{tabular}

Sumber: Data Primer, 2019.

Tabel 1 menunjukkan bahwa tingkat usia responden di lokasi penelitian relatif berusia produktif atau masa dewasa tengah yaitu 10 orang $(50 \%)$ dari 20 responden dengan kisaran usia antara 41 sampai 50 tahun. Kemudian di ikuti kisaran usia 31 sampai 40 tahun sebanyak 6 Orang (30\%), usia 21 - 30 tahun sebanyak 2 orang $(10 \%)$. Sedangkan yang memasuki lansia atau diatas 50 sebanyak 2 orang atau (10\%).

\section{Pendidikan}

Persentase responden menurut karakteristik pendidikan di daerah penelitian dapat dilihat pada Tabel 2.

Tabel 2. Persentase responden Menurut Pendidikan di Lokasi Penelitian Tahun 2019

\begin{tabular}{lcc}
\hline \multicolumn{1}{c}{ Tingkat Pendidikan } & $\begin{array}{c}\text { Jumlah Responden } \\
\text { (orang) }\end{array}$ & $\begin{array}{c}\text { Persentase } \\
(\%)\end{array}$ \\
\hline Tidak Berpendikan - SD & 11 & 55 \\
Tamat SD - SLTP & 5 & 25 \\
Tamat SLTP - SLTA & 4 & 20 \\
\hline Jumlah & 20 & 100 \\
\hline
\end{tabular}

Sumber : Data Primer, 2019

Tabel 2 menunjukkan bahwa secara umum masih sangat rendah, yaitu $55 \%$ tingkat tidak berpendidikan sampai Sekolah Dasar (SD) sebanyak 11 orang responden, dan diikuti oleh yang tamat Sekolah Dasar (SD) sampai Sekolah Lanjutan Tingkat Pertama (SLTP) sebanyak 5 orang responden $(25 \%)$, selanjutnya sebanyak 4 orang responden (20\%) tamat dari sekolah lanjutan tingkat pertama (SLTP) sampai Sekolah Lanjutan Tingkat Atas (SLTA) dari 20 orang sampel.

3. Jumlah Tangungan

Persentase responden menurut karakteristik jumlah tangungan di daerah penelitian dapat dilihat pada Tabel 3 .

\begin{tabular}{|c|c|}
\hline Tabel & 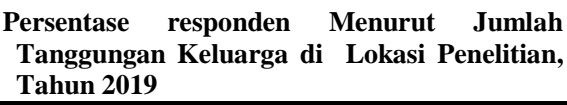 \\
\hline Tanggungan & $\begin{array}{l}\text { Jumlah Responden } \\
\text { (orang) }\end{array}$ \\
\hline $1-3$ orang & 12 \\
\hline$>4$ orang & 40 \\
\hline Jumlah & 100 \\
\hline
\end{tabular}

Tabel 3 menunjukkan bahwa persentase jumlah tanggungan keluarga petani dan pedagang sampel perkepala keluarga di lokasi penelitian pada kisaran $1-3$ Orang (60\%) atau 12 orang responden dan sisanya sebanyak $40 \%$ atau 8 orang sampel berada pada kisaran lebih dari 4 orang dalam satu kepala keluarga.

4. Pengalaman

Persentase responden menurut karakteristik pegalaman di daerah penelitian dapat dilihat pada Tabel 4 . 
Tabel 4. Persentase Responden Menurut Pengalaman di Lokasi Penelitian,Tahun 2019

\begin{tabular}{ccc}
\hline Pengalaman & $\begin{array}{c}\text { Jumlah Responden } \\
\text { (orang) }\end{array}$ & Persentase (\%) \\
\hline 1-5 Tahun & 7 & 35 \\
$6-10$ Tahun & 9 & 45 \\
$>$ 10 Tahun & 4 & 20 \\
\hline Jumlah & 20 & 100 \\
\hline Sumber: Data Primer, 2019 &
\end{tabular}

Sesuai hasil daftar wawancara responden, 9 orang $(45 \%)$ petani dan pedagang sampel di lokasi penelitian sudah cukup lama berusahatani kacang tanah dan kegiatan menjual atau memasarkan kacang tanah yaitu berada di kisaran 6-10 tahun, kemudian diikuti 7 orang (35\%) berada di kisaran $1-5$ Tahun, serta 4 orang $(20 \%)$ diantaranya berada di atas 10 tahun.

\section{Jumlah Anggota Keluarga}

Persentase responden menurut karakteristik jumlah anggota keluarga di daerah penelitian dapat dilihat pada Tabel 5.

Tabel 5. Persentase Responden Berdasarkan Jumlah Anggota Keluarga di lokasi Penelitian,Tahun 2019

\begin{tabular}{ccc}
\hline Anggota Keluarga & $\begin{array}{c}\text { Jumlah Responden } \\
\text { (Orang) }\end{array}$ & Persentase (\%) \\
\hline $3-4$ & 13 & 65 \\
$5-6$ & 5 & 25 \\
$7-8$ & 2 & 10 \\
\hline Jumlah & 20 & 100 \\
\hline
\end{tabular}

Sumber: Data Primer, 2019

Berdasarkan Tabel 5 bahwa responden yang memiliki jumlah anggota keluarga terbanyak yaitu berkisar 3-4 orang sebanyak 13 orang atau $65 \%$. Berdasarkan data tersebut menunjukkan sebagian besar responden mempunyai anggota keluarga lebih dari 3 orang, sehingga hal ini mempengaruhi petani responden dalam berusaha tani dan berdagang kacang tanah.

\section{Luas Lahan}

Persentase responden menurut karakteristik jumlah luas lahan di daerah penelitian dapat dilihat pada Tabel 6 .

\begin{tabular}{cccc} 
Tabel 6. Persentase Responden Berdasarkan Luas & Ren \\
& $\begin{array}{c}\text { Lahan, Jumlah } \\
\text { Penelitian, Tahun }\end{array}$ & $\begin{array}{c}\text { Bo19 } \\
\text { Bedengan, Di }\end{array}$ & Lokasi \\
\hline Luas & Lahan & Jumlah & Persentase \\
Lahan & Diusahakan & Responden & $(\%)$ \\
$($ Ha) & (Bedeng) & (Orang) & \\
\hline 0,5 & $3-5$ & 15 & 75 \\
1,0 & $>6$ & 5 & 25 \\
\hline Jumlah & - & 20 & 100 \\
\hline Sumber: Data Primer, 2019 & &
\end{tabular}

Tabel 6 menunjukkan persentase petani kacang tanah di lokasi penelitian memiliki luas lahan $0,5 \mathrm{Ha}$ hingga $1,0 \mathrm{Ha}$, lahan yang diusahakan $5-6$ bedeng oleh 15 responden (75\%) dan $(25 \%)$ atau 5 responden di antaranya mengusahakan lebih dari 6 bedeng. Ukuran bedeng diusahakan responden berusaha tani kacang tanah di lokasi penelitian bervariasi dengan ukuran 3-4 meter dan panjang 10 meter atau lebih. Pada umumnya lahan yang digunakan petani sampel di daerah penelitian adalah lahan milik sendiri.

\section{Saluran Pemasaran}

Berdasarkan hasil penelitian yang telah dilaksanakan pada pemasaran kacang tanah di Distrik Bugi Kabupaten Jayawijaya terdapat dua tahapan saluran pemasaran yaitu:

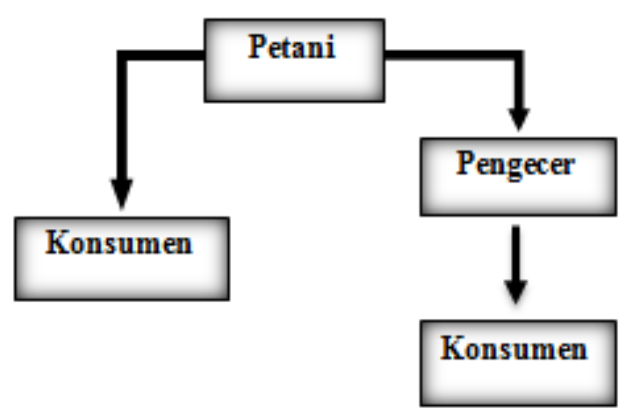

Gambar 1. Tahapan Saluran Pemasaran kacang tanah di Distrik Bugi Kabupaten Jayawijaya.

\section{Saluran Pemsaran I}

Pada saluran pemasaran I adalah saluran tetap. petani menjual kacang tanah kepada konsumen di pasar. Petani menjual hasil panen di pasar umum atau pasar tradisional kemudian dibeli oleh konsumen. Dapat dilihat pada Tabel 7.

Tabel 7. Volume Penjualan dan Harga yang Berlaku Pada Saluran I Tahun 2019

\begin{tabular}{llccc}
\hline No & Uraian & $\begin{array}{c}\text { Volume } \\
\text { Penjualan } / \mathrm{Kg}\end{array}$ & $\begin{array}{c}\text { Harga Beli } \\
\mathrm{Rp} / \mathrm{Kg}\end{array}$ & $\begin{array}{c}\text { Harga Jual } \\
\mathrm{Rp} / \mathrm{Kg}\end{array}$ \\
\hline 1 & Petani & 40 & - & 10.000 \\
2 & Konsumen & - & 10.000 & - \\
\hline \multicolumn{7}{l}{ Sumber : Data Primer, 2019} & &
\end{tabular}

Tabel 7 menunjukkan bahwa penjualan komoditi kacang tanah di saluran I, terlihat bahwa volume penjualan petani setelah dikonversikan sebanyak $40 \mathrm{Kg}$ kacang tanah dengan harga jual petani $\mathrm{Rp} 10,000 / \mathrm{Kg}$. Harga jual ditingkat petani menjadi harga beli bagi konsumen akhir. 


\section{Saluran Pemsaran II}

Pada saluran pemasaran II adalah saluran tidak tetap karena saluran ini melakukan usaha jual beli antara petani dan pengecer tidak setiap saat karena pengecer bukan pelanggan tetap tetapi pengecer melihat peluang pasar lalu mendatangi petani dan membeli kacang tanah untuk di jual kembali kepada konsumen. Dapat dilihat pada Tabel 9.

Tabel 9. Volume Penjualan dan Harga yang Berlaku Pada

\begin{tabular}{llccc}
\multicolumn{5}{c}{ Saluran II, Tahun 2019 } \\
\multirow{2}{*}{ No } & \multirow{2}{*}{ Uraian } & $\begin{array}{c}\text { Volume Penjualan } \\
/ \mathrm{Kg}\end{array}$ & $\begin{array}{c}\text { Harga Beli } \\
\mathrm{Rp} / \mathrm{Kg}\end{array}$ & $\begin{array}{c}\text { Harga } \\
\text { Jual/kg }\end{array}$ \\
\hline 1 & Petani & 40 & - & 10.000 \\
2 & Pengecer & 40 & 10,000 & 20.000 \\
3 & Konsumen & - & 20,000 & - \\
\hline
\end{tabular}

Sumber: Data Primer, 2019

Volume penjualan setelah di konversi dalam satuan kilo di tingkat petani dan pengecer tetap sama namun harga jual kedua saluran dari petani ke pengecer dan pengecer ke konsumen terjadi perubahan. Harga yang berlaku pada saluran II pedagang pengecer lebih banyak mendapatkan keuntungan dari volume penjualan $40 \mathrm{~kg}$ dengan harga jual Rp20,000/kg.

\section{Harga, Volume Beli dan Jual}

Harga jual di tinggkat petani merupakan harga beli di tingkat pedagang pengecer dan konsumen, harga jual di tingkat pedagang pengecer adalah harga beli di tingkat konsumen akhir. Perkembangan volume, harga beli dan jual dalam seminggu dilihat pada Tabel 10 .

\begin{tabular}{|c|c|c|}
\hline Tabel 10. & $\begin{array}{l}\text { Harga, Volume } \\
\text { Pengecer Dalam } \\
2019\end{array}$ & $\begin{array}{c}\text { Pembelian dan Penjualan } \\
\text { Seminggu Kepada Petani, }\end{array}$ \\
\hline \multicolumn{3}{|c|}{ Pembelian } \\
\hline Hari Beli & Volume (Kg) & Harga Beli $(\mathrm{Rp} / \mathrm{Kg})$ \\
\hline 1 & 40 & 400,000 \\
\hline 2 & 80 & 800,000 \\
\hline \multicolumn{3}{|c|}{ Penjualan } \\
\hline Hari Jual & Volume (Kg) & Harga jual (Rp/Kg) \\
\hline 1 & 40 & 800,000 \\
\hline 2 & 80 & $1,600,000$ \\
\hline
\end{tabular}

Tabel 10 menunjukkan bahwa volume pembelian hari pertama dalam seminggu di tingkat pengecer kepada petani sebanyak $40 \mathrm{~kg}$ dengan harga beli Rp.400.000 dan harga jual hari pertama di minggu yang sama Rp.800.000. Volume pembelian hari kedua dalam seminggu sebanyak $80 \mathrm{~kg}$ dengan harga beli Rp.800.000 dan harga jual hari kedua di minggu yang sama Rp.1,600,000.

\section{Biaya}

Biaya yang dimaksud dalam penelitian ini adalah keseluruhan pengeluaran dalam proses pemasaran pada tiap lembaga pemasara dari petani hingga konsumen yang tidak dapat dihindarkan di lokasi penelitian. Biaya mempunyai peran yang sangat penting dalam pengambilan keputusan menjalankan usaha pemasaran melalui setiap saluran pemasaran. Besarnya biaya yang dikeluarkan untuk saluran pemasaran sangat menentukan besar harga tiap lembaga pemasaran. Untuk mengetahui biaya pemasaran pada tiap saluran dapat dilihat pada Tabel 11.

Tabel 11. Biaya Pemasaran Kacang Tanah Pada Tiap Saluran Pemasaran Dalam Seminggu Di Distrik Bugi Kabupaten Jayawijaya, Tahun 2019

\begin{tabular}{|c|c|c|c|c|}
\hline No & Uraian & \multicolumn{3}{|c|}{ Biaya } \\
\hline 1 & Petani & Hari 1 (Rp) & \multicolumn{2}{|c|}{ Hari $2(\mathrm{Rp})$} \\
\hline & A. Biaya Transportasi & 70,000 & & 140,000 \\
\hline & B. Rusak & - & & - \\
\hline & C. Sewa Tempat & - & & - \\
\hline & D. Tenaga Kerja & - & & - \\
\hline \multicolumn{2}{|r|}{ Total Biaya } & & \multicolumn{2}{|c|}{ Rp140,000 } \\
\hline \multirow[t]{7}{*}{2} & Pengecer & Hari 1 (Rp) & Hari & $2(\mathrm{Rp})$ \\
\hline & A. Harga Beli & 400 & & 800 \\
\hline & B. Biaya Transportasi & 15 & & 30 \\
\hline & C. Rusak & - & & - \\
\hline & D. Sewa Tempat & - & & - \\
\hline & E. Kantong & - & & - \\
\hline & Total Biaya & & & 830,000 \\
\hline
\end{tabular}

Sumber : Data Primer, 2019

Tabel 11 menunjukkan bahwa biaya yang ditanggung oleh petani pada saluran pemasaran adalah biaya transportasi dari pusat produksi ke pasar tradisional di kota dua kali melakukan penjualan dalam seminggu, jadi dalam seminggu petani melakukan penjualan sebanyak dua kali dengan biaya saluran pemasaran Rp.140.000.

Biaya yang terdapat pada saluran pemasaran pengecer adalah biaya harga beli dengan biaya transportasi dalam melakukan pembelian dan penjualan, pembelian dan penjualan dapat dilakukan dua kali dalam seminggu dengan biaya saluran pemasaran sebesar Rp.830.000. Pengecer melakukan kegiatan penjualan di pasar tradisional yang ada di sekitaran kota wamena selain pasar tradisional jibama yakni pasar sinakma, pasar potikelek dan pasar misi. 


\section{Fungsi Pemasaran}

Fungsi pemasaran diperlukan dalam kegiatan pemasaran untuk memperlancar distribusi barang dan jasa dari tiap lembaga pemasaran yang terlibat. Secara umum fungsi pemasaran yang dilaksanakan lembaga pemasaran terdiri dari tiga fungsi yaitu fungsi pertukaran, fungsi fisik dan fungsi fasilitas. Fungsi pertukaran meliputi kegiatan - kegiatan yang dapat memperlancar perpindahan hak milik dari barang dan jasa yang dipasarkan.

\begin{tabular}{|c|c|c|c|c|c|c|}
\hline \multirow[t]{2}{*}{ Tabel 12} & & \\
\hline & \multicolumn{2}{|c|}{$\begin{array}{l}\text { Fungsi-Fungsi Pemasaran Yang Dilaksanakan Oleh } \\
\text { Lembaga Pemasaran Pada Tiap Saluran Pemasaran } \\
\text { Kacang Tanah Di Distrik Bugi Kabupaten Jayawijaya, } \\
\text { Tahun } 2019\end{array}$} & & & & \\
\hline Saluran & \multicolumn{6}{|c|}{ Fungsi Pemasaran } \\
\hline $\begin{array}{l}\text { Lembaga } \\
\text { Pemasaran }\end{array}$ & \multicolumn{2}{|c|}{$\begin{array}{c}\text { Fungsi } \\
\text { Pertukaran }\end{array}$} & Fungsi Fisik & \multicolumn{3}{|c|}{ Fungsi Fasilitas } \\
\hline Saluran I & Jual Beli & Kemas & Angkut Simpan & Resiko & Biaya & Info pasar \\
\hline Petani & $\sqrt{ }$ & $\sqrt{ }$ & $\sqrt{1}$ & - & $\sqrt{1}$ & - \\
\hline Pengecer & $\sqrt{ }$ & $\sqrt{ }$ & $\sqrt{ }$ & - & $\sqrt{ }$ & $\sqrt{ }$ \\
\hline Saluran II & Jual Beli & Kemas & Angkut Simpan & Resiko & Biaya & Info pasar \\
\hline Petani & $\sqrt{ }$ & $\sqrt{ }$ & $\sqrt{ }$ & - & $\sqrt{ }$ & - \\
\hline
\end{tabular}

Keterangan : $\sqrt{ }=$ Melakukan kegiatan fungsi pemasaran.

- = Tidak melakukan kegiatan fungsi pemasaran.

Berdasarkan Tabel 12 diatas diketahui bahwa pada saluran pemasaran satu petani melakukan fungsi pertukaran berupa penjualan, fungsi fisik berupa pengangkutan dan fungsi fasilitas berupa pembiayaan.

\section{Struktur Pasar}

Struktur pasar didefinisikan sebagai sifat atau karakteristik pasar. Faktor penting yang diperlukan dalam penentuan struktur pasar meliputi jumlah pembeli dan penjual yang terlibat, sifat atau keadaan produk, kondisi keluar masuk pasar dan informasi pasar berupa biaya, harga dan kondisi pasar. Petani dan lembaga - lembaga pemasaran yang terlibat dalam kegiatan pemasaran kacang tanah di pasar tradisional jibama menghadapi struktur pasar yang berbeda.

\section{Perilaku Pasar}

Perilaku pasar adalah pola tingkah laku lembaga-lembaga pemasaran yang menyesuai-kan dengan struktur pasar dimana lembaga tersebut melakukan kegiatan penjualan dan pembelian serta bentuk-bentuk keputusan yang diambil dalam menghadapi struktur pasar tersebut. Perilaku pasar meliputi kegiatan pembelian dan penjualan, penentuan harga, dan kerjasama antar lembaga pemasaran.

\section{KESIMPULAN DAN SARAN}

\section{Kesimpulan}

1. Saluran pemasaran yang ada di lokasi penelitian ada dua saluran:

1) Petani - Konsumen. atau (saluran pemasaran nol tingkat).

2) Petani — Pengecer - Konsumen. atau (saluran pemasaran satu tingkat).

Dengan kedua saluran pemasaran yang ada, petani lebih mudah mendapatkan informasi pasar mengenai harga dan bentindak sebagai penentu harga karena petani menjumpai langsung ke pasar membawa hasil produksinya, tidak membutuhkan biaya untuk mendapatkan informasi harga di pasar. Biaya pemasaran pada petani dan pengecer tergolong sangat rendah karena kedua saluran pemasaran di lokasi penelitian sangat pendek dipengaruhi oleh konsumen kacang tanah berasal dari penduduk lokal dan biaya yang dikeluarkan petani hanya biaya transportasi dari pusat produksi ke pasar dan harga beli di tingkat pengecer dari petani sedangkan biaya rusak, sewa tempat, tenaga kerja, kantong dan lainlain tidak ada.

2. Fungsi pemasaran yang dilakukan di lokasi penelitian tergolong sangat sederhana. Fungsi-fungsi pemasaran yang aktif dilakukan di tiap lembaga dalam penelitian ini antara lain:

a. Petani

Petani melakukan fungsi pertukaran berupa fungsi penjualan langsung di pasar tradisional, fungsi fisik berupa kegiatan pengemasan dan pengangkutan, fungsi fasilitas berupa pembiayaan.

b. Pedagang Pengecer

Pengecer melakukan fungsi pertukaran berupa pembelian pada petani dan penjualan kepada konsumen, fungsi fisik berupa pengemasan dan pengangkutan, fungsi fasilitas berupa fungsi informasi pasar dan pembiayaan.

3. Struktur pasar yang dihadapi petani dan pengecer kacang tanah di Distrik Bugi bersifat pasar bersaing sempurna dengan jumlah petani yang banyak, tidak dapat mempengaruhi harga dan petani bebas keluar 
masuk pasar, hal ini terlihat melalui keseragaman kualitas dari produk kacang tanah yang dihasilkan petani. Informasi harga yang dimiliki petani dan pengecer cukup baik tanpa biaya dan disesuaikan pengalaman hari penjualan sebelumnya.

Perilaku pasar yang berjalan di tingkat petani kegiatanp pembelian dan Penjualan. Petani kacang tanah yang ada di Distrik Bugi menjual hasil panennya di pasar tradisional Jibama yang terletak di pusat kota. Penentuan harga di tingkat petani menentukan harga jual kacang tanah disesuaikan dengan pengamatan perkembangan keadaan pasar dan ditentukan sesuai pengalaman waktu penjualan sebelumnya dan juga sesuai kualitas produksi kacang tanah dalam memberikan kepuasan konsumen. Ukuran kecil besarnya ikatan penjualan kacang tanah mempengaruhi penentuan harga jual di tingkat petani di musim tertentu.

Pembelian yang dilakukan oleh pedagang pengecer dilakukan dengan sistem pembayaran secara tunai. Jumlah kacang tanah yang dibeli dari petani sebanyak 80 ikat atau dua noken dan jumlah yang dijual oleh pengecer sebanyak 160 ikat, pada umumnya habis terjual. Satuan penjualan di tingkat saluran pemasaran satu dan dua sama yaitu dalam bentuk ikatan kepada konsumen. Penentuan harga di tingkat petani dan pengecer sama namun ukuran ikatan di tingkat pengecer lebih kecil dari ukuran penjualan di tingkat petani.

\section{Saran}

Berkaitan dengan penelitian ini, agar supaya petani di Distrik Bugi Kabupaten Jayawijaya dapat melakukan usaha pemasaran kacang tanah dengan efektif, perlu adanya penanganan pasca panen untuk meningkatkan dan mengukur efektivitas pemasaran yang di ukur dengan kualitas produk, kuantitas produk dan waktu sesuai dengan yang di harapkan untuk memberikan nilai tambah dan ubah satuan penjualan dari ikat ke satuan kilo $(\mathrm{kg})$. Perlu adanya peran pemerintah sebagai fasilitator dalam hal menyediakan pasar yang bisa menampung komoditas panggan kacang tanah, menyediakan operasinal petani guna mewujudkan pemasaran komuditi pangan yang efektif dan efisien dan meningkatkan semangat petani untuk memanfaatkan lahan dan memproduksi yang lebih besar. Berkaitan dengan penelitian ini, Agar supaya petani di distrik Bugi dapat melakukan usaha pemasaran kacang tanah dengan efektif, Perlu adanya peran pemerintah sebagai fasilitator dalam hal menyediakan pasar swalayan yang bisa menampung komoditas panggan kacang tanah, menyediakan operasinal petani guna mewujudkan pemasaran komuditi pangan yang efektif dan efisien dan meningkatkan semangat petani untuk memanfaatkan lahan dan memproduksi yang lebih besar.

Tingkat komunikasih dan kerjasama antara petani dengan pengecer perlu di terapkan sebagai pelanggan tetap dan sistem pemasaran yang baik untuk memudahkan mendistribusikan komoditi kacang tanah dari petani dengan harga yang stabil.

\section{DAFTAR PUSTAKA}

Aryani, R et al. 2009. Prosedur Klinik Keperawatan Pada Mata Ajar Kebutuhan Dasar Manusia. Jakarta: TIM.

Ginting N. 2015. Manajemen pemasaran. Bandung: Yrama Widya.

Limbong W.H., Sitorus. 1987. Pengantar Tataniaga Pertanian. Fakultas Pertanian Institut Pertanian Bogor, Bogor. 